\title{
Assessment of Post Graduates (PG) for Extra Oral Radiograph Techniques by DOPS (Direct Observation of Procedural Skills) Method.
}

\author{
Dr.Apeksha Dhole ( Balpande) \\ (Professor, Department of Oral Medicine and Radiology, V.S.P.M.DC\&RC,Nagpur,India)
}

\begin{abstract}
Extraoral radiographs plays important role in the diagnosis of certain maxillofacial pathologies. It is necessary to improve accuracy in this technique so as to protect patient from unnecessary exposure. In the present study, nine post graduate students from the deparment of Oral Medicine and Radiology were assessed with DOPS method.Immediate feedback was given and technique was reassessed and the comparison was made between DOPS 1 and 2.Students feedback for DOPS was also obtained.The present study results shwed that DOPS is one of the best method to asess students procedural skills.It also hepls in immediate improvement of the skills.
\end{abstract}

Keywords: DOPS, extraoral, feedback, postgraduate, radiographs,

\section{Introduction}

Though the radiology has changed from conventional to digital in last few years, radiologist should aware of the basic principles and techniques used in conventional radiology. Extra- oral radiography being part of conventional radiology, is taught to the students at BDS level in theory classes. But post-graduates should be mastered in theory as well as practical. In practical summative assessment,around $60 \%$ marks are allocated to this topic.Considering the importance of this topic in academic as well as in community practice,I chose it so as to make students competent.Proficiency in procedural skills is an important objective of training for post graduates. It was observered that self guided or self regulated learning can provide effective learning environment for students. However, self guided learning require periodic supervision. As a result of constant changes in clinical education,the necessity of implementing appropriate new method of evaluation has become more succinct than before. Keeping in mind, the principles of Adult-learning and self- directed leaning, DOPS is one of the best method for procedural skill assessment ${ }^{1,2}$.Thus, the present study was planned to assess extra oral radiographic skill by DOPS in post graduates of Oral medicine and radiology so as to improve accuracy in taking extra oral radiographs and protect patients from unnecessary radiation exposure.

\section{Objectives-}

1. To assess the status of procedural skills in PG students.

2. To compare and evaluate effectiveness of DOPS method.

3. To assess feedback from PGs regarding the assessment tool.

\section{Inclusion Criteria-}

1. Patient in whom 'lateral oblique for body of mandible',view is indicated.

2. Patient willing to participate.

Exclusion criteria-

1. Patient with neck deformities.

2. Pregnant females and children.

\section{Materials And Methods-}

Material required were-

1. Extra-oral cassettes and films

2. Lead apron

3. Gloves

\section{Method}

A study was commenced after an approval from 'Institution Ethical Committee'. This is an observational study. 9 PG students from department of Oral Medicine \& Radiology were selected and asked to prepare topic, an 'extraoral radiography techniques'. Students were made aware that they will be assessed by DOPS method. DOPS method was explained to the students as well as patients. Each student took one extraoral 
radiograph (lateral oblique for body of mandible) of patient in whom it is indicated and were assessed by DOPS method with preformatted validated checklist. DOPS form which is available on online, few modifications were done. Immediately after completion of the procedure students feedback was obtained. This was DOPS 1 assessment. The similar assessment was carried out after a week as DOPS 2.The results obtained after each assessment were compared. The students feedback obtained after assessment were also evaluated and ststistical analysis was performed. (Table1)

\section{Results}

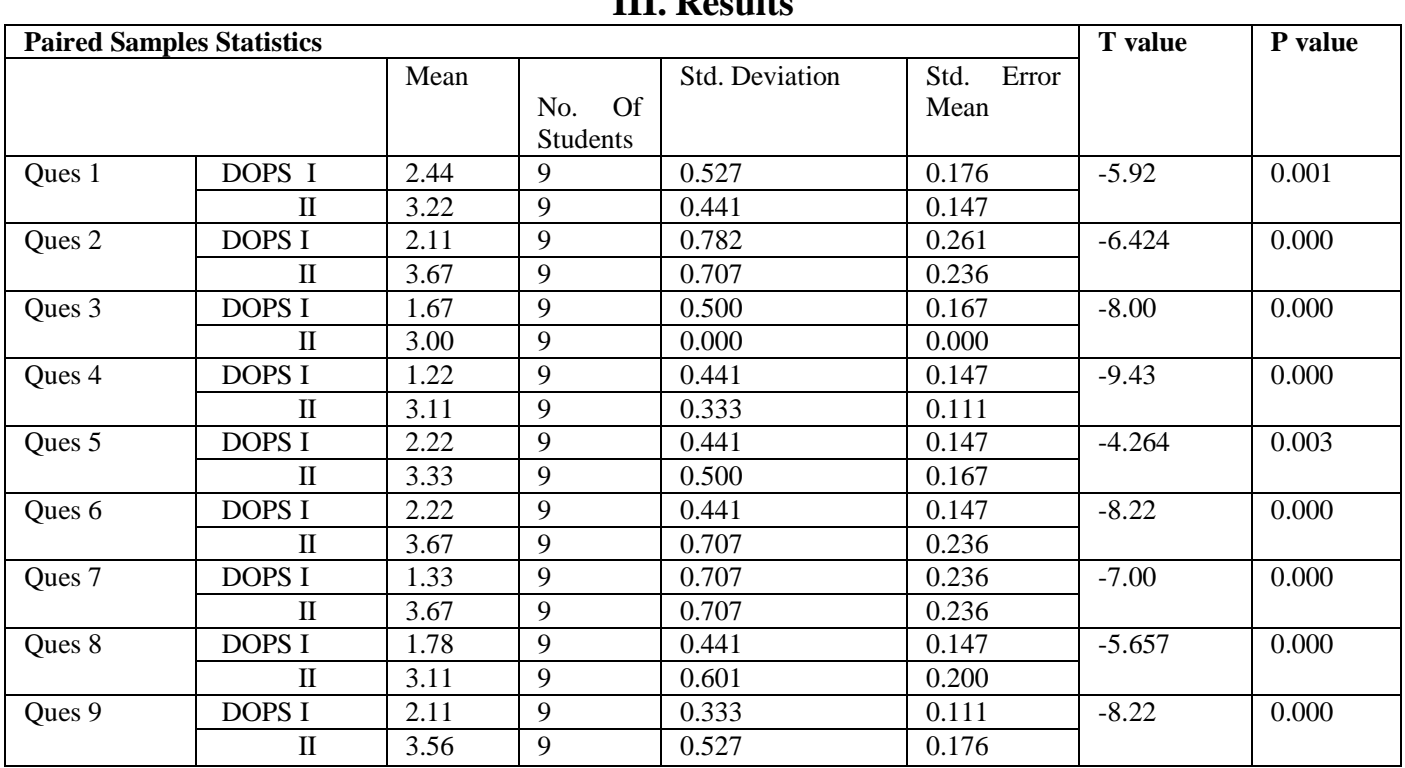

Table 1: Paired Samples Statistics for DOPS criterias

The DOPS criterias under which the students were assessed are

Que 1- Demonstrate knowledge of indications, relevant anatomy and technique

Que 2- Explains procedure to patient, obtains informed consent where appropriate

Que 3- Demonstrate appropriate pre- procedure preparation.

Que 4- Infection control

Que 5- Technical ability

Que 6-Communication skills with patient/staff

Que 7- Minimises use of ionising radiation for procedures involving $\mathrm{x}$ - rays

Que 8-Demonstrate situation awareness

Que 9- Quality of report of procedure

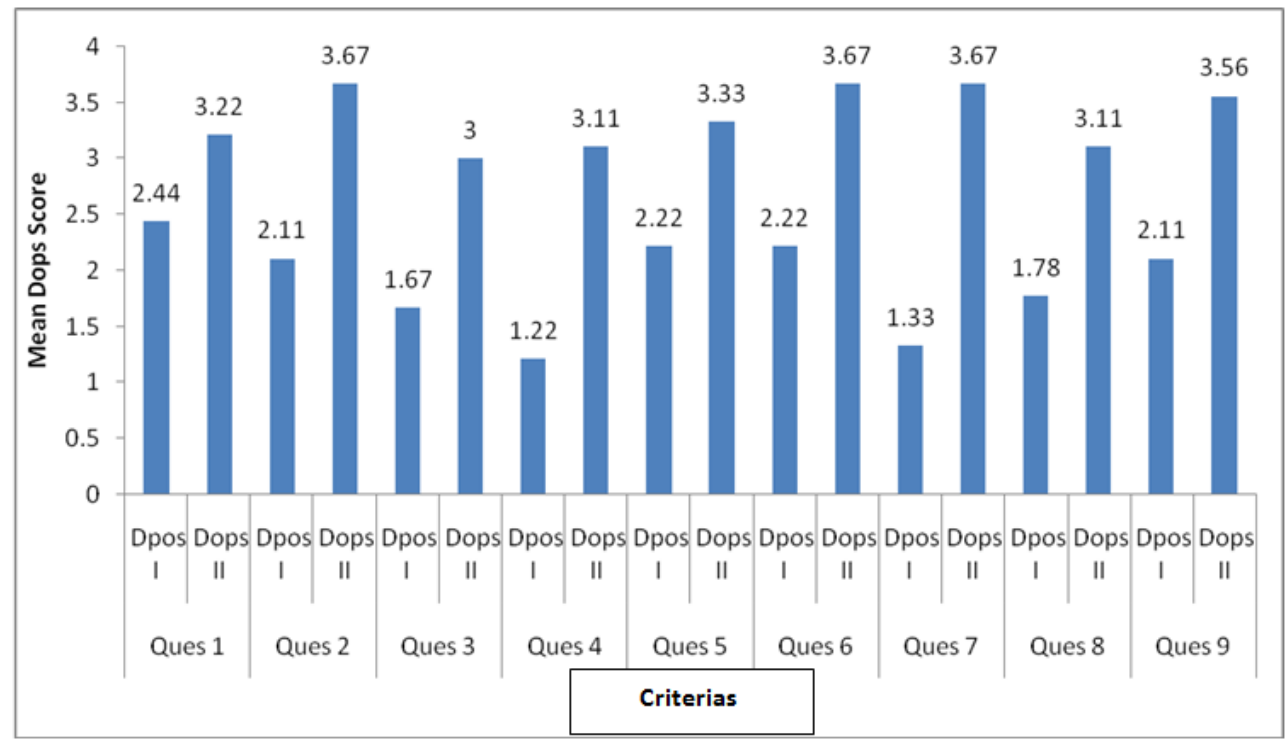

Graph 1: Mean score for DOPS criterias 
Finally Assessor evaluated Trainee as whether the procedure was completed satisfactorily or not and whether the student need more assessment.The mean score achieved after DOPS II score (3.11) which was statistically significant after DOPS 1 score 1.57 (Paired $\mathrm{t}$-test, $\mathrm{p}$ value $<0.00$ ). (Graph 1)

\section{Discussion}

Innovations in teaching -learning methods necessities the innovations in evaluation pattern.Traditional clinical learning pattern for post graduates is to observe, assist their teachers, seniors, peers.A review study on assessment of procedural skills found that there were no validated methods of procedural performance assessment.OSCE (Objective structured clinical examination), log books were advised initially as an assessment tool. ${ }^{3,4}$ But OSCE leads to assessment of procedural skills in fragmented manner with no opportunity to observe the examinee carrying out a complete procedure. While DOPS (Direct Observation of Procedural Skills), mini-CEX are more reliable and valid workplace based assessment ${ }^{6,7}$.DOPS is the observation and evaluation of a procedural skill performed by a trainee on a real patient. ${ }^{5,6}$ The procedural skills assessed using DOPS may range from simple to complex.The main reason why DOPS was used in the present study as it include assessment of procedural skills, evaluation of a specific patient encounter, performance of procedure on actual patient, immediate feedback on performance.

In the present study, students have shown significant improvement among DOPS I and II criteria wise but overall performance require more DOPS assessment so as to increase proficiency. Profanter C. and Peranthoner A $(2015)^{5}$ showed that DOPS represent an efficient method in teaching clinical skills over tutor system when subjected to final year medical students. Hengameh $\mathbf{H}$, Afsaneh et al $(2015)^{7,1}$ also showed that the DOPS test is more effective on skills level promotion of the nursing students in cmparision with the traditional evaluation method.In the present study, Feedback obtained from the students after DOPS showed students satisfaction and almost all student liked the method and wanted to apply for other procedural skill assessmentThough DOPS is better method of assessment Naseem N (2013) ${ }^{3}$ when reviewed 30 articles published during 2000 to 2012 and suggested DOPS has good reliability and acceptability but there was no objective evidence about its validity, feasibility and educational impact.I really enjoyed performing my project. It helps in strengthening teacher-student relation.

\section{References}

[1]. Roghieh N, Fateme $\mathbf{H}$ et al, The effect of applying direct observation of procedural skills (DOPS) on nursng students clinical skills: A randomized clinical trial. Iran J Nurs Midwifery Res. . 2013 July-Aug; 18(4):290-293.

[2]. Touchie C, S. Humphrey et al, Teaching and assessing procedural skills: a qualitative study. BMC Medical education 2013, 13:69.

[3]. http://www.biomedcentral.com/1472-6920/13/69.

[4]. Naseem N, Valildity,Relliability,feasibility, acceptability and educational impact of direct observation of procedural skills (DOPS).J of the college of physicians and surgeons Pakistan,2013, vol. 23(1):77-82.

[5]. Roghieh N, Fateme $\mathbf{H}$ et al, The effect of formative evaluation using 'direct observation of procedural skills'(DOPS) method on the extent of learning practical skills among nursing students in the ICU.IranJ Nurs Midwifery Res. 2013 Jul-Aug;18(4):290-293

[6]. K L Karanth, S Kanagasaba et al, Structured Program For Final-Year Undergraduate Students To Improve Clinical Skills To Prepare For Effective Patient Management. The Internet Journal of Gynecology and Obstetrics 2014, Volume 19 Number 1

[7]. Profanter C. Perathoner A, DOPS (Direct observation of procedural skills) in undergraduate skills-lab: Does it work? Analysis of Skills- performance and curricular side effects.GMS GMA 2015, vol 32 (4).

[8]. Hengameh H, Afsaneh et al, The effect of applying Direct Observation of procedural skills (DOPS) on nursing students clinical skills: A randomized clinical trial. Global J of health sciences; vol 7;2015. 